\title{
Research on ultrasonically assisted electrochemical machining process
}

\author{
Sebastian Skoczypiec
}

Received: 17 November 2009 / Accepted: 7 June 2010 / Published online: 26 June 2010

(C) The Author(s) 2010. This article is published with open access at Springerlink.com

\begin{abstract}
Electrochemical machining (ECM) is an important technology in machining difficult-to-cut materials and to shape free-form surfaces. In ECM, material is removed by electrochemical dissolution process, so part is machined without inducing residual stress and without tool wear. To improve technological factors in electrochemical machining, introduction of electrode tool ultrasonic vibration is justifiable. This method is called as ultrasonically assisted electrochemical machining (USAECM). In the first part of the paper, the analysis of electrolyte flow through the gap during USAECM has been presented. Based on computational fluid dynamic methods, multiphase, turbulent and unsteady electrolyte flow between anode and cathode (under assumption that cavitation phenomenon occurs) has been analysed. Discussion of the obtained solutions is the base to define optimal conditions of electrolyte flow in case of USAECM process. The second part of the paper is connected with experimental investigations of USAECM process. Classic experimental verification of obtained results in case of machining is extremely difficult, but influence of the ultrasonic vibration can be observed indirectly by changes in technological factors (in comparison to machining without ultrasonic intensification), whereas results of numerical simulation give possibility to understand reason and direction of technological factors changes. Investigations proved that ultrasonic vibrations change conditions of electrochemical dissolution
\end{abstract}

\footnotetext{
S. Skoczypiec $(\bowtie)$
}

Institute of Production Engineering,

Cracow University of Technology,

Al. Jana Pawla II 37, 31-864, Krakow, Poland

e-mail: skoczypiec@m6.mech.pk.edu.pl and for optimal amplitude of vibration gives possibility to decrease the electrode polarisation.

Keywords Electrochemical machining • Ultrasonic vibration - CFD · Hybrid methods

\section{Introduction}

Electrochemical machining (ECM) is an important technology in machining difficult-to-cut alloys and to shape free form surfaces [7]. In ECM, material is removed by electrochemical dissolution process, so part is machined without inducing residual stress and without tool wear. In comparison to conventional methods, the main advantages of ECM are as follows [4]:

- Material removal rate does not depend on material hardness

- There is no tool wear during machining (when machining parameters are optimal)

- Good surface quality after machining (there is no significant changes in surface layer)

Because of these advantages, ECM is applied in space, aircraft and domestic industries [7].

One of the methods to improve technological factors in electrochemical machining is introduction of electrode tool ultrasonic vibration (ultrasonically assisted electrochemical machining, USAECM). Generally, application of ultrasound to fluid causes a chaotic, turbulent flow. Propagation of the sound wave through the ultrasonically irradiated media creates pressure drop, which can break forces holding the liquid molecules together and generates microbubbles. The literature describes several types of cavitation, but in aspect of 
electrochemical dissolution process, the most interesting is transient cavitation [1]. In this case, cavitation bubbles grow extensively and then undergo an energetic collapse, which usually occurs in less then one microsecond time [14]. Single bubble collapse leads to the local generation of extreme conditions of temperature and pressure in very short time. 'Hot spot' theory estimates that, during the collapse, temperature reaches about $5,000 \mathrm{~K}$ and pressure is approximately 1,700 bar [14]. In case of ultrasonically assisted electrochemical machining, ultrasonic vibration gives possibility for creating cavitation microbubbles near the workpiece and electrode surface. Dissolved in electrolyte gas, products of dissolution and increased electrolyte temperature during machining cause that very good conditions for cavitation bubbles to grow occur in the gap. Process of the microbubbles collapse in area adjacent to electrode gives possibility for increasing the intensification of mass and electric charge transportation. As was presented in $[5,6,8,9,13]$, ultrasonic vibrations have the significant influence on the kinetics of electrode processes conditions and increases the rate of electrochemical dissolution.

In the paper, analysis of electrolyte flow through the gap in USAECM process has been presented. To solve the problem of electrolyte flow through the gap, computational fluid dynamic (CFD) methods have been applied. Results of these investigations give possibility to predict the distribution of cavitation bubbles along the gap. It can be helpful during experimental data analysis and in USAECM manufacturing processes designing.

\section{Problem formulation}

In case of USAECM, ultrasonic vibration frequency is about $20 \mathrm{kHz}$; it gives wavelength about $70 \mathrm{~mm}$ for seawater. The ultrasonic wavelength is much greater than typical interelectrode gap during machining. Moreover, in majority of cases, the amplitude of vibration is lesser than $10 \mu \mathrm{m}$; therefore, for small interelectrode gap thickness $(\approx 0.1 \mathrm{~mm})$, distance from anode to cathode is varied only $\pm 10 \%$. Therefore, it is reasonable to assume that influence of ultrasonic vibration on electrochemical dissolution process manifest itself through cavitations and its consequences.

To analyse influence of ultrasonic vibration on electrochemical dissolution process, it is necessary to solve the problem of electrolyte flow through the gap during the machining. In case of ECM, the flow is threedimensional, multiphase and unstable. Usually the electrolyte flow analysis is carried out under assumption that the electrolyte properties are constant along the gap thickness. When machining process is carried out in steady state, such assumption is sufficient. However, in case of machining in unstable or quasi-stable state (as in USAECM case), changes of electrolyte properties in direction normal to the workpiece should not be neglected because ultrasonic vibration of the electrode tool introduce additional (normal to the workpiece) electrolyte velocity component.

Analytical solution of the Navier-Stokes equations for multiphase, turbulent and unstable electrolyte flow is complicated. In USAECM additionally, special effort should be also applied for identification of cavitation regions in the gap. In this case, good alternative is application of CFD. Numerical solution of the NavierStokes equations gives possibility to obtain values of electrolyte pressure and velocity distribution in whole gap area. Application of full cavitation model [10] gives possibility to include cavitation effects in two-phase flow thorough the gap.

\section{Numerical modeling of electrolyte flow through the gap}

\subsection{Assumptions}

The presented model two-dimensional flow between two electrodes has been taken into account. Scheme and the boundary conditions of the problem are presented on the Fig. 1. The anode (workpiece) is treated as a stable wall and the cathode (electrode tool) is treated as vibrating wall with $20 \mathrm{kHz}$ frequency (period of vibration $T=50 \mu \mathrm{s})$. During simulations, three
Fig. 1 Scheme of modeled gap, $g=1 \mathrm{~mm}$, frequency of vibration $f=20 \mathrm{kHz}$

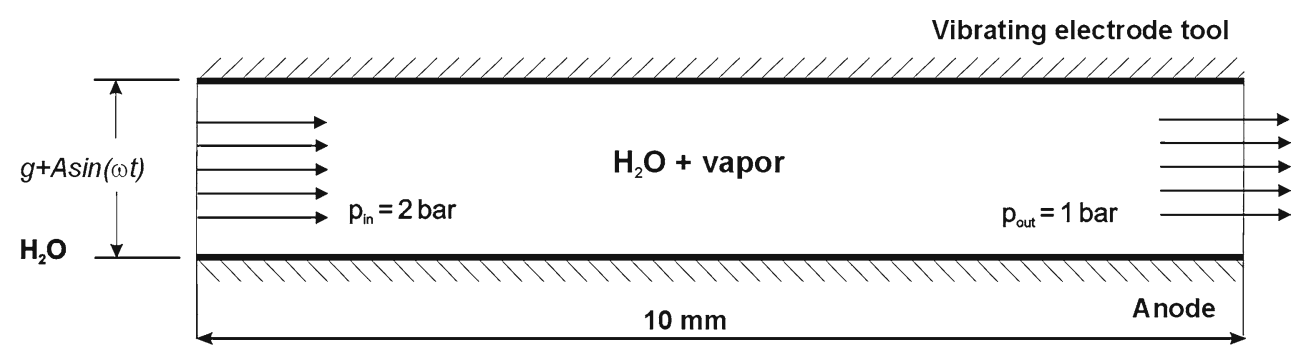


levels of ultrasound amplitude have been taken into account: $A=2.5 \mu \mathrm{m}, A=5 \mu \mathrm{m}$ and $A=10 \mu \mathrm{m}$. The gap thickness $g=1 \mathrm{~mm}$ is bigger than typical gap thickness during ECM. For $g<1 \mathrm{~mm}$ problem of numerical model, stable solution occurs.

The Fluent software has been applied to solve the problem of electrolyte flow along such a gap. According to above presented discussion, cavitation phenomenon presence in the gap has been assumed. Therefore, the electrolyte in the gap consists of three phases:

- Pure electrolyte

- Electrolyte vapour

- Non-condensable dissolved gas

To solve multiphase flow between the cathode and anode, based on the Euler-Euler approach, mixture model has been applied [3]. The electrolyte and gas phases have been treated mathematically as interpenetrating continua and the concept of phase volume fraction $\alpha$ has been introduced. The $\alpha$ is a continuous function in space and time, and for the mixture in the gap, the following formula is fulfilled:

$\alpha_{e}+\alpha_{v}+\alpha_{g}=1$

where $\alpha_{e}$ is the electrolyte volume fraction, $\alpha_{v}$ is the vapour volume fraction and $\alpha_{g}$ is the non-condensable gas fraction. The mixture density and viscosity have been described by the following equations:

$\rho_{m}=\alpha_{e} \rho_{e}+\alpha_{v} \rho_{v}+\alpha_{g} \rho_{g}$

$\mu_{m}=\alpha_{e} \mu_{e}+\alpha_{v} \mu_{v}$

where $\rho_{e}, \rho_{v}, \rho_{g}, \mu_{e}$ and $\mu_{v}$ are the density of mixture phases.

\subsection{Equations of the electrolyte flow}

Flow of the electrolyte mixture through the gap has been described by the following set of equations [3]:

1. Continuity equation of the mixture:

$$
\frac{\partial}{\partial t}\left(\rho_{m}\right)+\nabla \times\left(\rho_{m} \mathbf{v}_{m}\right)=\dot{m}
$$

where $\mathbf{v}_{\mathbf{m}}$ is the electrolyte mass-averaged velocity and $\dot{m}$ represents mass transfer between electrolyte and its vapour due to cavitation.

2. Momentum equation of the mixture (obtained by summing individual momentum equations for all phases):

$$
\begin{aligned}
& \frac{\partial}{\partial t}\left(\rho_{m} \mathbf{v}_{m}\right)+\nabla \times\left(\rho_{m} \mathbf{v}_{m} \mathbf{v}_{m}\right) \\
& \quad=-\nabla p+\nabla \times\left[\mu_{m}\left(\nabla \mathbf{v}_{m}\right)+\nabla \mathbf{v}_{m}^{T}\right]+\mathbf{F}
\end{aligned}
$$

3. Volume fraction equation for the vapour phase (obtained from the continuity equation for vapour):

$$
\frac{\partial}{\partial t}\left(\alpha_{v} \rho_{v}\right)+\nabla \times\left(\alpha_{v} \rho_{v} \mathbf{v}_{\mathbf{m}}\right)=0
$$

Numerical solution of the above-mentioned equations gives possibility to obtain mixture velocity $v_{m}(x, y, t)$, mixture pressure $p(x, y, t)$ and electrolyte vapour phase $\alpha_{v}(x, y, t)$ distribution in the gap.

\subsection{Mass transfer through cavitation}

The applied cavitation model is based on full cavitation model presented in [10]. The phase exchange rate expressions have been derived from a reduced Rayleigh-Plasset equation for single bubble dynamics, and their final form has been described by the following equations:

$$
\begin{aligned}
& R_{e}=C_{e} \frac{\sqrt{k}}{\sigma} \rho_{e} \rho_{v}\left[\frac{2}{3} \frac{p_{\mathrm{sat}}-p_{\infty}}{\rho_{e}}\right]^{1 / 2}\left(1-f_{v}-f_{g}\right) \\
& R_{c}=C_{c} \frac{\sqrt{k}}{\sigma} \rho_{e} \rho_{v}\left[\frac{2}{3} \frac{p_{\infty}-p_{\mathrm{sat}}}{\rho_{e}}\right]^{1 / 2} f_{v}
\end{aligned}
$$

where $R_{e}$ are $R_{c}$ are the vapour generation and condensation rate terms, respectively, $C_{e}=0.02$ and $C_{e}=$ 0.01 are the empirical constants [10] and $f_{v}$ and $f_{g}$ are the phase mass fraction $\left(f_{i}=\alpha_{i} \frac{\rho_{i}}{\rho_{m}}\right)$. The phase change threshold $p_{v}$ is estimated from Eq. 10 which describes the local values of the turbulent pressure fluctuation and from Eq. 11:

$p_{\text {turb }}=0.39 \rho k$

$p_{\text {turb }}=p_{\text {sat }}+p_{\text {turb }} / 2$

where $p_{\text {sat }}$ is the electrolyte vapour pressure saturation. Due to the problems occurring in electrolyte vapour pressure saturation estimation, surface tension for water at temperature $300 \mathrm{~K}$ has been assumed.

\subsection{Results of numerical simulation}

During analysis of numerical simulation results, main attention has been focused on pressure $p$ and vapour phase $\alpha_{v}$ changes in the gap. Results have shown that flow in the gap is periodical with time constant equal to ultrasonic vibration period $T$. In the Figs. 2 and 3, changes of the pressure and vapour phase fraction in time, for amplitude of vibration $A=5 \mu \mathrm{m}$, have been presented. When electrode moves in direction opposite to machining direction, the pressure in the area adjacent to anode decreases. In the same time, amount of vapour in this area increases up to $14 \%$ of electrolyte volume. When electrode tool moves towards the anode, 


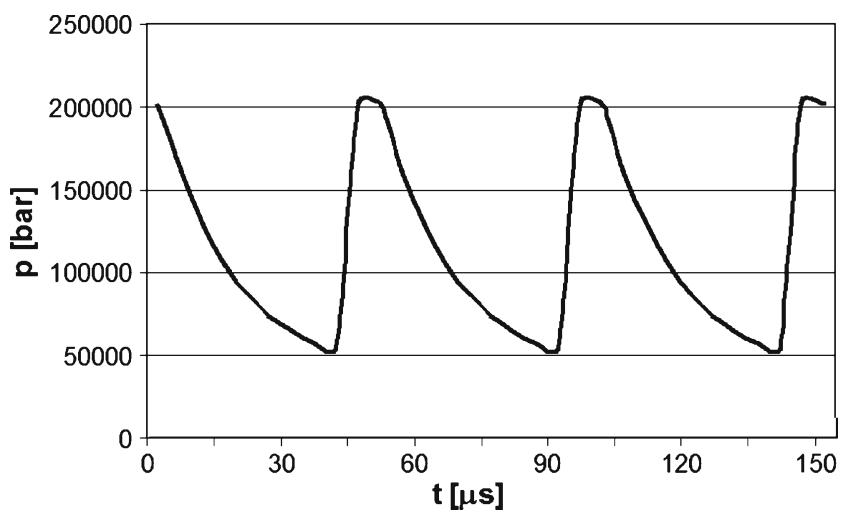

Fig. 2 Changes of the electrolyte pressure in the layer close to the anode surface for time period $150 \mu$ s, amplitude of electrode vibration $A=5 \mu \mathrm{m}$ and period of electrode vibration $T=50 \mu \mathrm{s}$

pressure increases and reaches maximal value for time $t=n T(50,100$ and $150 \mu \mathrm{s})$. In this moment, amount of vapour is minimal. Such a relation of pressure and vapour phase fraction can point that, after the phase of cavitation bubbles growth, rapid collapse appear. For each value of analysed amplitude, character of pressure and vapour phase fraction changes was similar; however, range of pressure and vapour phase fraction depends on amplitude of vibration.

In Figs. 4, 5, 6 and 7, comparisons of the pressure and vapour volume fraction distribution along the gap for $A=2.5 \mu \mathrm{m}, A=5 \mu \mathrm{m}$ and $A=10 \mu \mathrm{m}$ have been presented. These relations showed the distributions for two characteristic moments of the machining: $t_{1}=$ $(n T+T / 2)$ and $t_{2}=n T$, when size of the gap is $1 \mathrm{~mm}$. One can state that:

- For $t=t_{1}$ (Figs. 4 and 5), value of the maximal pressure depends on amplitude of the ultrasonic

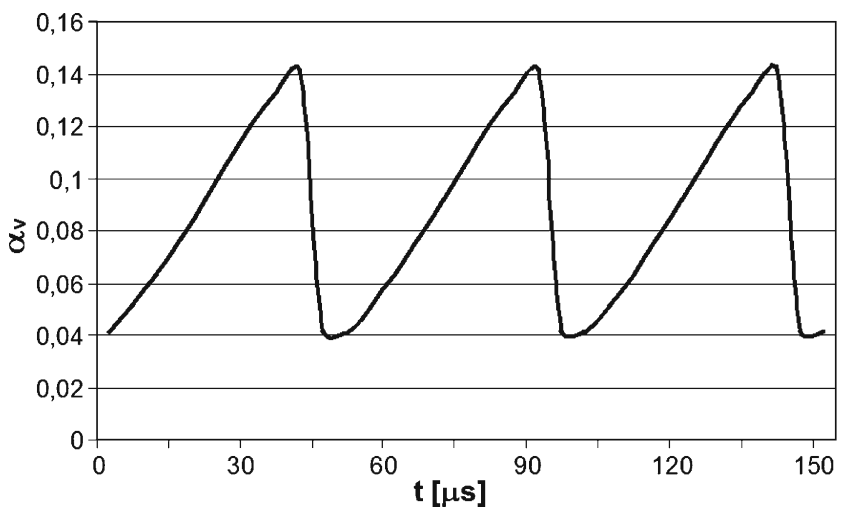

Fig. 3 Changes of the vapour volume fraction in the layer close to the anode surface for time period $150 \mu \mathrm{s}$, amplitude of electrode vibration $A=5 \mu \mathrm{m}$ and period of electrode vibration $T=50 \mu \mathrm{s}$

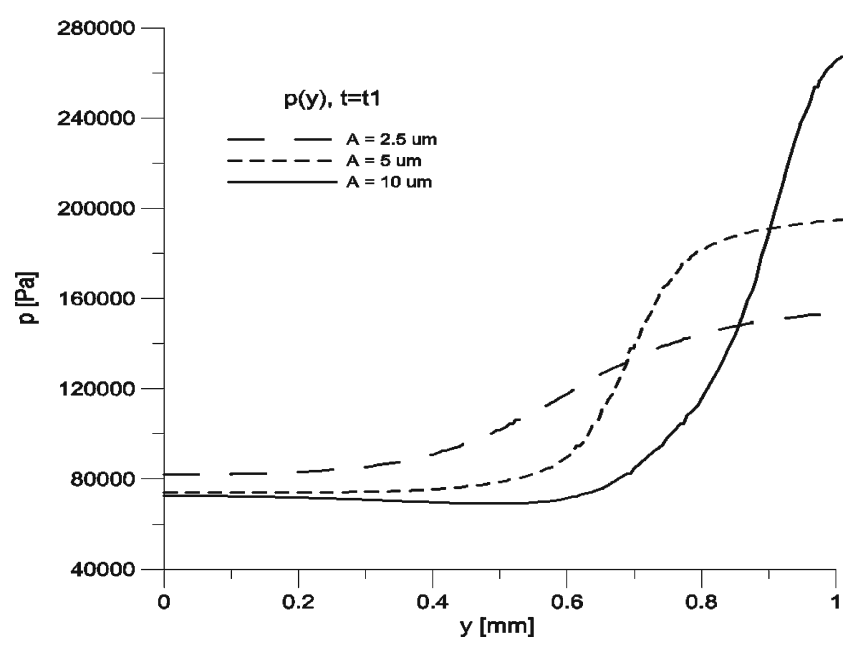

Fig. 4 Comparison of the pressure distribution along the gap thickness for $A=2.5 \mu \mathrm{m}, A=5 \mu \mathrm{m}, A=10 \mu \mathrm{m}, t=(n T+$ $T / 2$ ), $y=0 \mathrm{~mm}$-anode surface, $y=1 \mathrm{~mm}$-electrode tool surface

vibration and appears in area close to the electrode tool. Maximal pressure drop in the gap has been observed for $A=10 \mu \mathrm{m}$. For analysed amplitudes, pressure and vapour volume fraction in areas adjacent to the anode have similar value $(p \approx 0.8 \mathrm{bar}$, $\alpha_{v} \approx 0.1$. One can notice that distribution of cavitation bubbles along the gap is non-uniform, and for $A=2.5 \mu \mathrm{m}$, maximal intensity of cavitation is only in areas close to the anode

- For $t=t_{2}$ (Figs. 6 and 7) maximal pressure value is in areas close to the anode and also depends on amplitude of ultrasonic vibration (maximal for $A=$

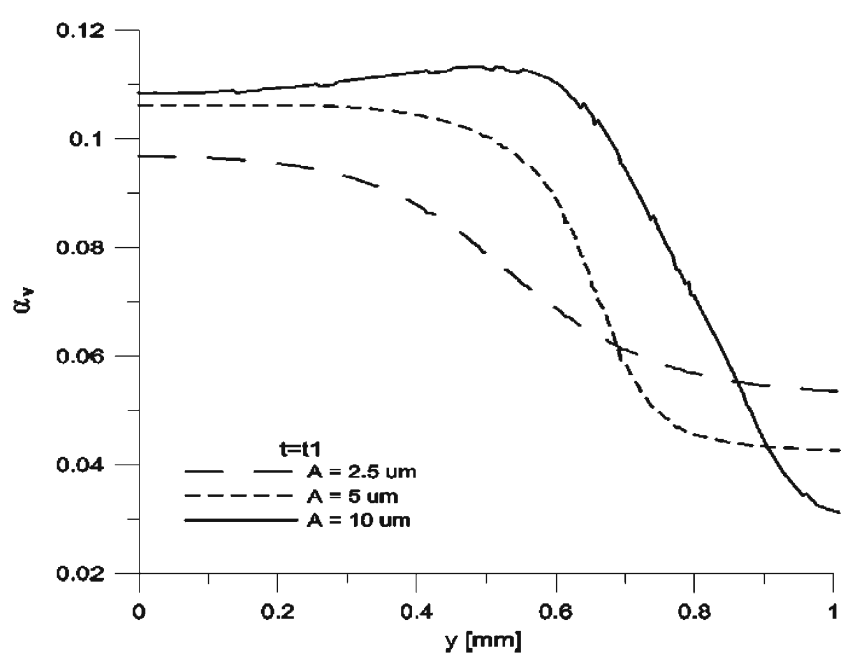

Fig. 5 Comparison of the vapour volume fraction $\alpha_{v}$ distribution along the gap thickness for $A=2.5 \mu \mathrm{m}, A=5 \mu \mathrm{m}, A=$ $10 \mu \mathrm{m}, t=(n T+T / 2), y=0 \mathrm{~mm}$-anode surface, $y=1 \mathrm{~mm}-$ electrode tool surface 


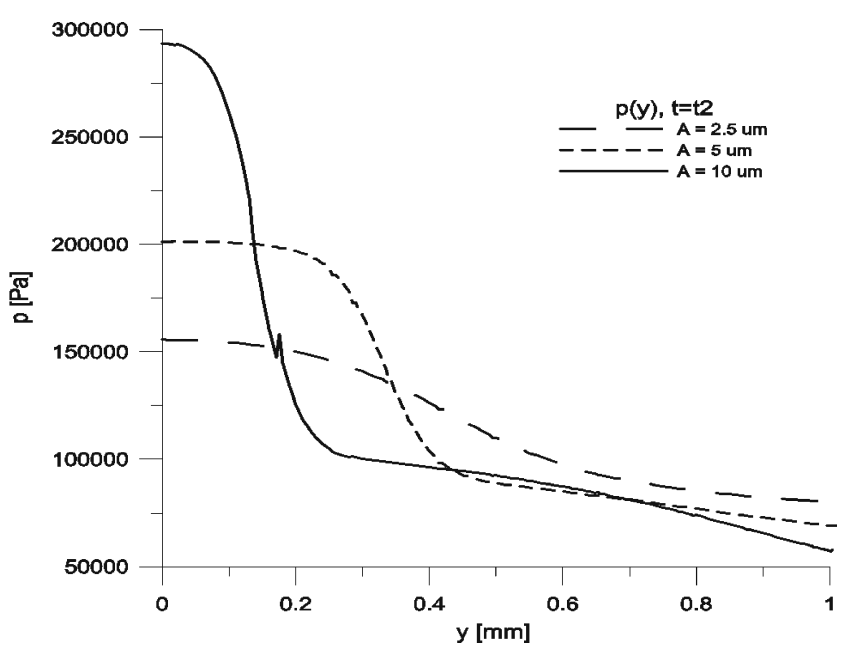

Fig. 6 Comparison of the pressure distribution along the gap thickness for $A=2.5 \mu \mathrm{m}, A=5 \mu \mathrm{m}, A=10 \mu \mathrm{m}, t=n T, y=$ $0 \mathrm{~mm}$-anode surface, $y=1 \mathrm{~mm}$-electrode tool surface

$10 \mu \mathrm{m})$. Maximal intensity of cavitation is in layers of electrolyte adjacent to the cathode.

From presented relations, one can state that ultrasonic vibrations are responsible for pressure gradient in direction normal the electrolyte flow. Value of the pressure drop depends on amplitude of ultrasonic vibration. Thickness of the electrolyte layer, where cavitation appears with its maximal intensity depends on vibration amplitude (from $0.25 \mathrm{~mm}$ for $A=2.5 \mu \mathrm{m}$ up to $0.7 \mathrm{~mm}$ for $A=10 \mu \mathrm{m})$. Increase of ultrasonic vibration amplitude results in increase of cavitation intensity inside the interelectrode gap (not only in areas adjacent to electrodes).

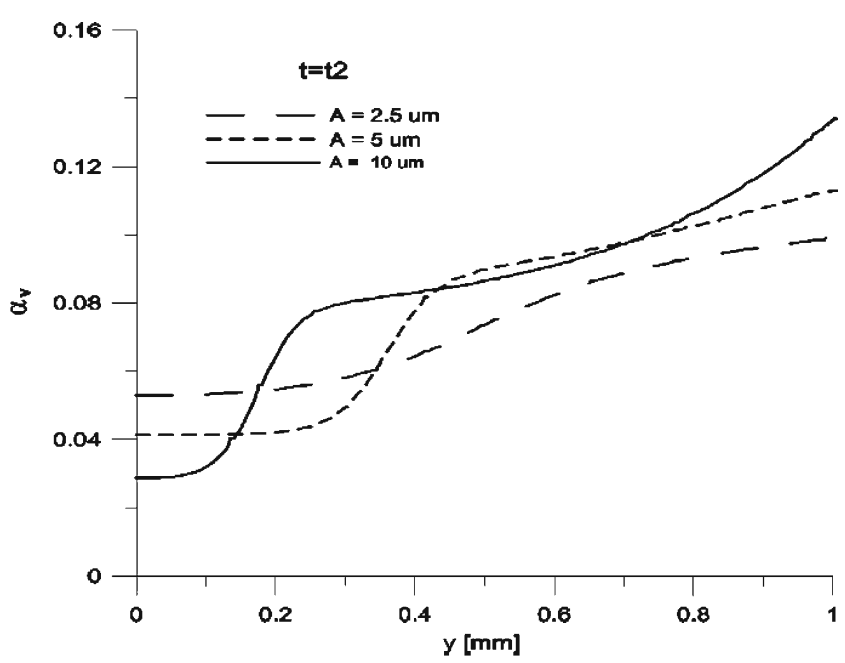

Fig. 7 Comparison of the vapour volume fraction $\alpha_{v}$ distribution along the gap thickness for $A=2.5 \mu \mathrm{m}, A=5 \mu \mathrm{m}, A=10 \mu \mathrm{m}$, $t=n T, y=0 \mathrm{~mm}$-anode surface, $y=1 \mathrm{~mm}$-electrode surface

\subsection{Discussion of the numerical simulation results in aspect of electrochemical process}

Transport of ions in the gap is driven by migration (transport driven by electric forces), convection and diffusion. In areas of electrolyte adjacent to the anode surface, migration and convection play less significant role than diffusion, which is the main transport mechanism via anode-electrolyte layer. Increase of anode ion concentration gradient increases the speed of anode dissolution, and the value of concentration polarisation is mainly connected with electrolyte hydrodynamics conditions in the gap. As has been shown during numerical simulation, cathode ultrasonic vibration generates cavitation phenomena in the gap. Cavitation bubbles in electrolyte can occur in two forms [2]:

- As homogeneous cavitation: Temporary thermal motions in electrolyte can cause microscopic voids which grow into bubbles.

- As heterogeneous cavitation: Weaknesses occur at the boundary between the electrolyte and the solid (e.g. electrode wall) and then grow into bubbles.

Dissolved in electrolyte gas, products of dissolution and increase of electrolyte temperature during machining cause that, in the gap, very good conditions for bubble collapse occur [12]. In the above presented model, noncondensable, with equal for whole volume mass friction, has been assumed. In real ECM, dissolution product concentration changes along gap thickness. Close to the anode electrolyte, temperature and amount of hydrogen are higher, what cause better physical conditions for bubble creations in this area (products of dissolution-gas, heat and sludge in electrolyte decrease a tensile strength necessary to bubble creation [12]). One can state that, in these areas, cavitation occurs with higher intensity than simulation has shown.

After bubble growth, the phase of rapid collapse starts. The bubble collapse near the anode surface produces mechanism of microjet impact on this surface. The potential energy of expanded bubble is converted into kinetic energy of liquid jet motion. Such a jet can reach velocity about $100 \mathrm{~m} / \mathrm{s}[1,14]$. The extremely fast bubble collapse causes local electrolyte refreshment and increase of concentration gradient. This effect is responsible for depolarisation and depassivation what results in material allowance thickness and removal rate increase during USAECM [11].

Results of numerical simulation prove that electrode ultrasonic vibrations change the character of electrolyte flow through the gap. Experimental verification of obtained results in case of electrochemical machining because of the gap size and short time of discussed 
phenomena is extremely difficult. However, the ultrasonic vibration influence can be observed indirectly by changes in technological factors (in comparison to machining without ultrasonic intensification) whereas results of numerical simulation gives possibility to understand reasons and direction of technological factors changes.

\section{Experimental investigation on USAECM process}

\subsection{Research methodology}

The main goal of experimental investigations was to determine the main characteristics between technological factors and process parameters. The research has been carried on in The Institute of Advanced Manufacturing Technology [11]. The scheme of test stand has been presented in Fig. 8. Electrode tool is displaced in direction of machined surface with velocity $v_{f}$ and electrolyte flows into interelectrode space through the hole in the sample.

Taking into account results of analysis of phenomena occurring into interelectrode gap during machining, the research plan has been developed. The investigated factors have been presented in Table 1. Based on machined allowance thickness, it is possible to calculate machining gap size in steady-state $S_{k}$ :

$S_{k}=a-h$

where $h$ is depth of machining. Additionally, taking into account $a$ and current density $j$ during machining,

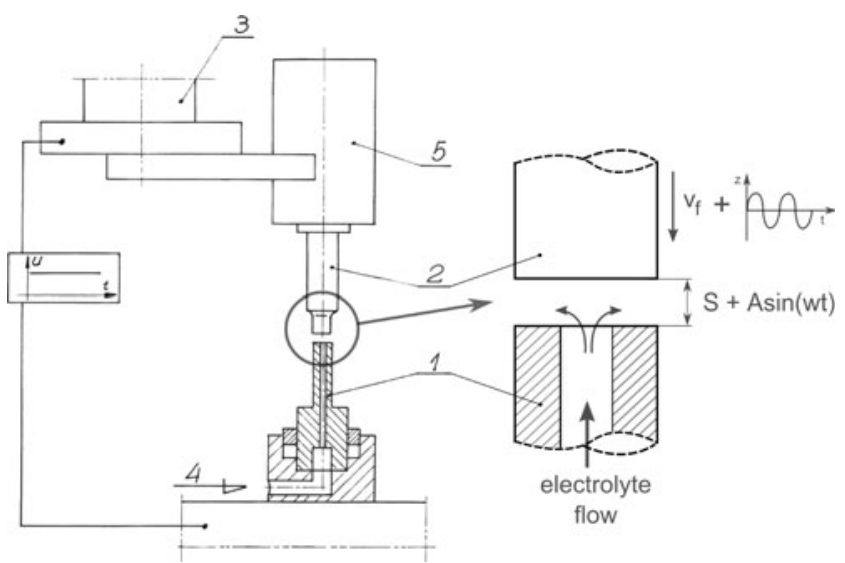

Fig. 8 Scheme of test stand for experiments: 1 workpiece, 2 electrode tool, 3 tool plate, 4 electrolyte supplying, 5 ultrasonic head, $A$ amplitude of ultrasonic vibration, $S$ interelectrode gap thickness, $v_{f}$ electrode feed rate
Table 1 USAECM research factors

\begin{tabular}{|c|c|c|c|}
\hline & Symbol & Min & Max \\
\hline \multicolumn{4}{|l|}{ Investigated factor } \\
\hline Interelectrode voltage & $U[\mathrm{~V}]$ & 8 & 20 \\
\hline Electrode feed rate & $v_{f}[\mathrm{~mm} / \mathrm{min}]$ & 0.2 & 1.4 \\
\hline $\begin{array}{l}\text { Power of ultrasonic } \\
\text { vibrations }\end{array}$ & $P[\mathrm{~W}]$ & 40 & 120 \\
\hline \multicolumn{4}{|l|}{ Output factors } \\
\hline $\begin{array}{l}\text { Thickness of machined } \\
\text { allowance }\end{array}$ & $a[\mathrm{~mm}]$ & & \\
\hline Current density & $j\left[\mathrm{~A} / \mathrm{mm}^{2}\right]$ & & \\
\hline \multicolumn{4}{|l|}{ Constant factors } \\
\hline $\begin{array}{l}\text { Initial thickness of } \\
\text { interelectrode gap }\end{array}$ & \multicolumn{3}{|c|}{$S_{0}=0.1 \mathrm{~mm}$} \\
\hline Depth of machining & \multicolumn{3}{|c|}{$h=0.9 \mathrm{~mm}$} \\
\hline Machining area (Fig. 8) & \multicolumn{3}{|c|}{$F=47 \mathrm{~mm}^{2}$} \\
\hline Machined material & \multicolumn{3}{|c|}{1.2063 steel } \\
\hline Electrode material & \multicolumn{3}{|c|}{ brass } \\
\hline Electrolyte & \multicolumn{3}{|c|}{$\begin{array}{c}15 \% \text { water solution } \\
\text { of } \mathrm{NaNO}_{3}\end{array}$} \\
\hline
\end{tabular}

it is possible to calculate electrochemical machinability $\eta k_{v}$ :

$\eta k_{v}=\frac{V}{j t}$

where machined volume $V=a F$ ( $F$-machined area) and $t=\left(h+S_{0}\right) / v_{f}$-machining time.

The main goal of the research was to state how the ultrasonic vibration changes the course of electrochemical machining process; therefore, two series of research have been carried out for machining with ultrasonic vibrations and machining without ultrasonic vibrations $(P=0 \mathrm{~W})$. Comparison of ECM and USAECM processes has been made under the following assumptions:

- Electrochemical dissolution is carried on in the same condition $\left(U, v_{f}, \kappa, T_{e}\right.$, electrodes material, electrolyte inlet and outlet are the same)

- Amplitude of ultrasonic vibrations $A<0.2 S_{k}$

- Sonochemical reactions influence on electrolyte properties are neglected

- Ultrasonic vibration influence on electrochemical process manifest itself by electrodes depolarization and depassivation

In case of USAECM, machining vibrating with ultrasonic frequency electrode moves towards the workpiece surface with $v_{f}$ feed rate. After some time of machining, the dissolution process becomes the quasistate; it means that phenomena in the gap are identical for each period of vibrations. Therefore, the gap thick- 
ness can be described as a function of machining time as follows:

$$
S(t)=S(t+n T)
$$

what means that allowance is machined with the following conditions:

$\Delta a(t)=\int_{0}^{T}\left(\eta k_{v}\right)(t) j(t) d t$

$\Delta a(t)=v_{f} T$

$\Delta a(t)=\Delta a(t+n T)$

Taking into account the above-mentioned assumptions, process of electrochemical dissolution in steady and quasi-steady state can be described by the following equations:

$S_{k}=\frac{\eta k_{v} \kappa(U-E)}{v_{f}}$

$j=\kappa \frac{U-E}{S_{k}}=\frac{v_{f}}{\eta k_{v}}$

where $S_{k}$-thickness of the interelectrode gap in steady (quasi-steady) state, $j$-current density, $U-$ interelectrode voltage, $E$-electrode polarisation, $\eta k_{v}$ - coefficient of electrochemical machinability, $\kappa-$ electrolyte conductivity and $v_{f}$-electrode feed rate. Based on Eqs. 15, 16 and 17, relation between gaps in ECM and USAECM process has been described by the following formula:

$$
\frac{S_{\mathrm{kECM}}}{S_{\mathrm{kUSAECM}}}=\frac{\left(\eta k_{v}\right)_{\mathrm{ECM}}\left(U-E_{\mathrm{ECM}}\right)}{\left(\eta k_{v}\right)_{\mathrm{USAECM}}\left(U-E_{\mathrm{USAECM}}\right)}
$$

and relations between current density in ECM and USAECM are described as follows:

$$
\frac{j_{\mathrm{ECM}}}{j_{\mathrm{USAECM}}}=\frac{\left(U-E_{\mathrm{ECM}}\right) S_{\mathrm{kUSAECM}}}{\left(U-E_{\mathrm{USAECM}}\right) S_{\mathrm{kUSAECM}}}
$$

Taking into account Eqs. 20 and 21, current density in USAECM process is as follows:

$$
j_{\mathrm{USAECM}}=\frac{j_{\mathrm{ECM}}\left(\eta k_{v}\right)_{\mathrm{ECM}}}{\left(\eta k_{v}\right)_{\mathrm{USAECM}}}
$$

From Eq. 22 results, that current density in USAECM process can be changed only by change of electrochemical machinability coefficient $\eta k_{v}$. Taking into account the above presented assumptions, relations (23) and (24) are as follows:

$$
S_{\mathrm{kECM}}=\frac{\left(\eta k_{v}\right)_{\mathrm{ECM}} \kappa\left(U-E_{\mathrm{ECM}}\right)}{v_{f}}
$$

$S_{\mathrm{kUSAECM}}=\frac{\left(\eta k_{v}\right)_{\mathrm{USAECM}} \kappa\left(U-E_{\mathrm{USAECM}}\right)}{v_{f}}$

and Eq. 22, it is possible to achieve electrode polarisation for ECM and USAECM for the same conditions of machining $\left(U, v_{f}, \kappa\right)$. The unknowns in relations (22), (23) and (24) are $E_{\mathrm{ECM}}, E_{\mathrm{USAECM}}$ and $\left(\eta k_{v}\right)_{\text {USAECM }}$, while $\kappa, U$ and $v_{f}$ are machining parameters and $S_{\mathrm{kECM}}, S_{\mathrm{kUSAECM}}$ and $\left(\eta k_{v}\right)_{\mathrm{ECM}}$ are results from experiments 12 . The electrochemical machinability coefficient $\left(\eta k_{v}\right)_{\mathrm{ECM}}$ for ECM has been calculated based on volume of machined material (13).

\subsection{Discussion of the results}

The results of investigations and analysis of phenomena occurring into machining area have been presented below. From relationship $S_{k}(U)$ (Fig. 9), one can state that, for constant electrode feed rate, interelectrode voltage increase causes also the gap thickness increase. For interelectrode voltage, $U<10 \mathrm{~V}$ gap is the smallest and almost identical for USAECM and ECM process. For small gaps, cavitation intensity and connected with this local pressure and temperature increase are high and occur along whole gap thickness, what despite of electrode polarisation decrease for USAECM process (Fig. 10) leads to decrease of electrochemical machinability coefficient (Fig. 11). With voltage increase, thickness of the interelectrode gap also increases, what is in agreement with Eq. 18; however, in case of USAECM, gap thickness is higher. It can be explained by decrease of cavitation intensity (it is localised only

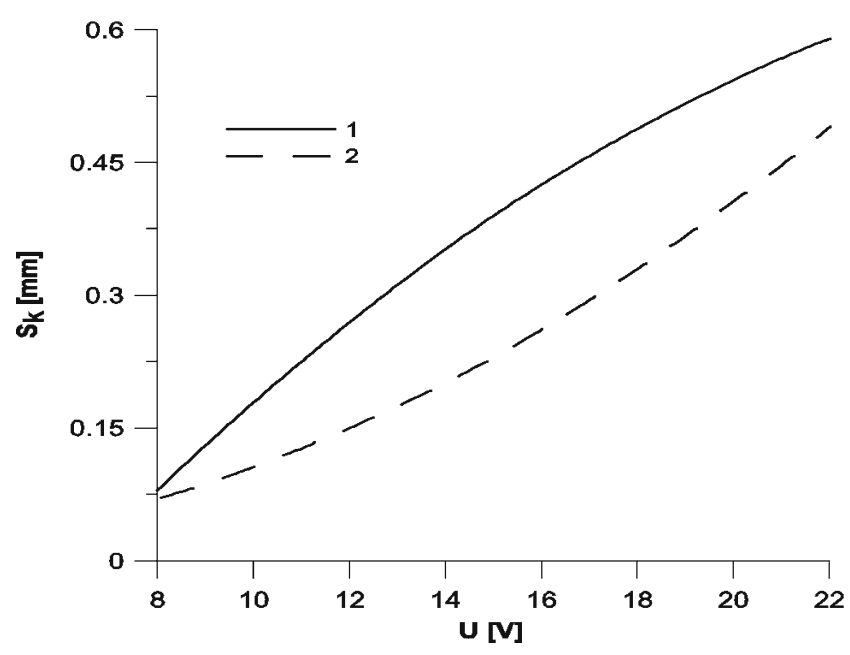

Fig. 9 Relation between interelectrode voltage $U$ and thickness of the interelectrode gap $S_{k}$; parameters of machining: electrode feed rate $v_{f}=0.8 \mathrm{~mm} / \mathrm{min}$, electrolyte inlet pressure $p_{e}=$ $0.3 \mathrm{MPa} ; 1$ USAECM $(A=4.8 \mu \mathrm{m}), 2 \mathrm{ECM}$ 


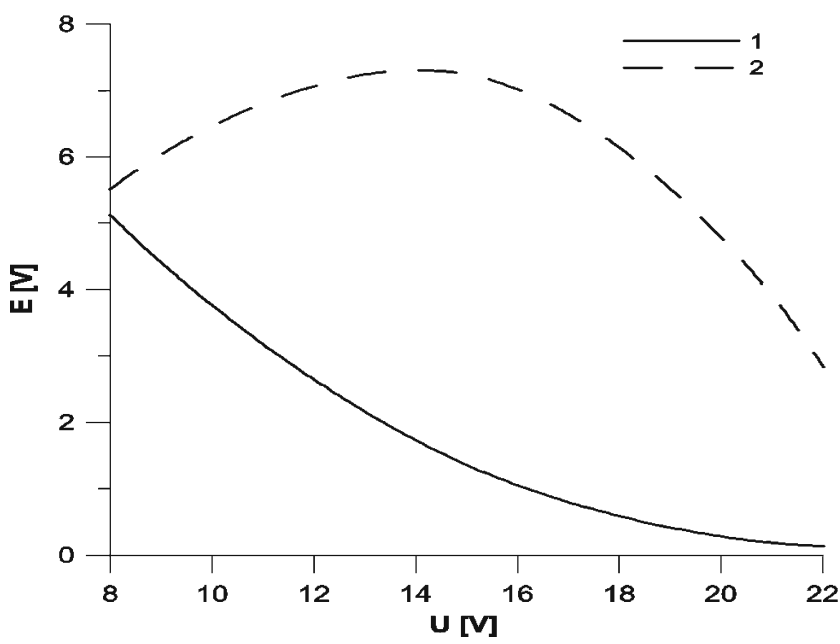

Fig. 10 Relation between interelectrode voltage $U$ and electrode polarisation $E$; parameters of machining: electrode feed rate $v_{f}=$ $0.8 \mathrm{~mm} / \mathrm{min}$, electrolyte inlet pressure $p_{e}=0.3 \mathrm{MPa}$; USAECM $A=4.8 \mu \mathrm{m}$

close to anode surface), and therefore, depolarisation and depassivation effect become dominating.

From relation $E(U)$ for both investigated processes (Fig. 10) results that electrode polarisation depends on voltage $U$ and introduction of electrode ultrasonic vibrations significantly decrease $E$; however, amount of $E$ drop is connected with vibrations amplitude $A$ (Fig. 12).

During experiment, the increase of current density for USAECM process has been noticed. According to Eq. 22, it is connected with decrease of electrochemical machinability coefficient (Fig. 11). Taking into account

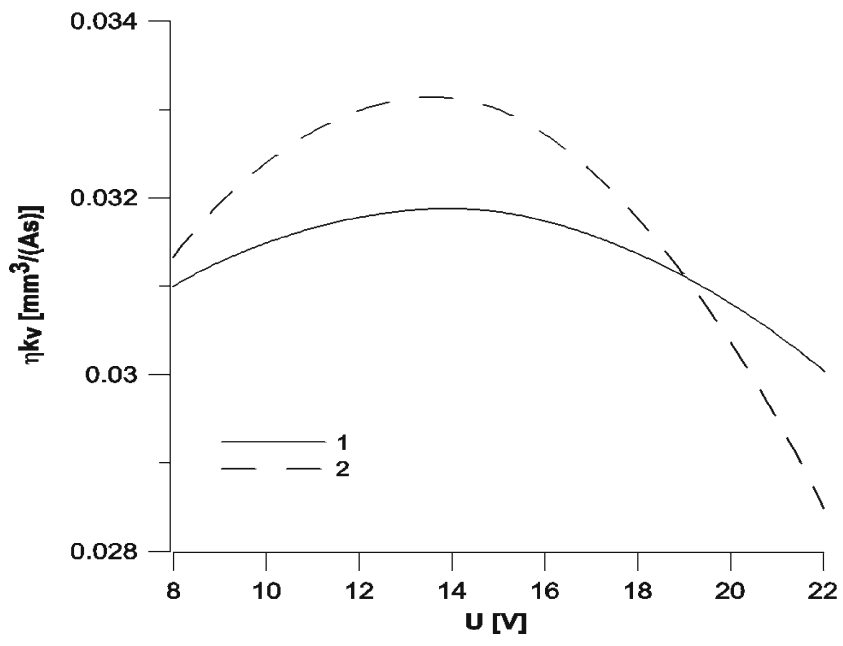

Fig. 11 Relation between interelectrode voltage $U$ and coefficient of electrochemical machinability $\eta k_{v}$; parameters of machining: electrode feed rate $v_{f}=0.8 \mathrm{~mm} / \mathrm{min}$, electrolyte pressure $p_{e}=0.3 \mathrm{MPa}$, USAECM- $A=4.8 \mu \mathrm{m}$

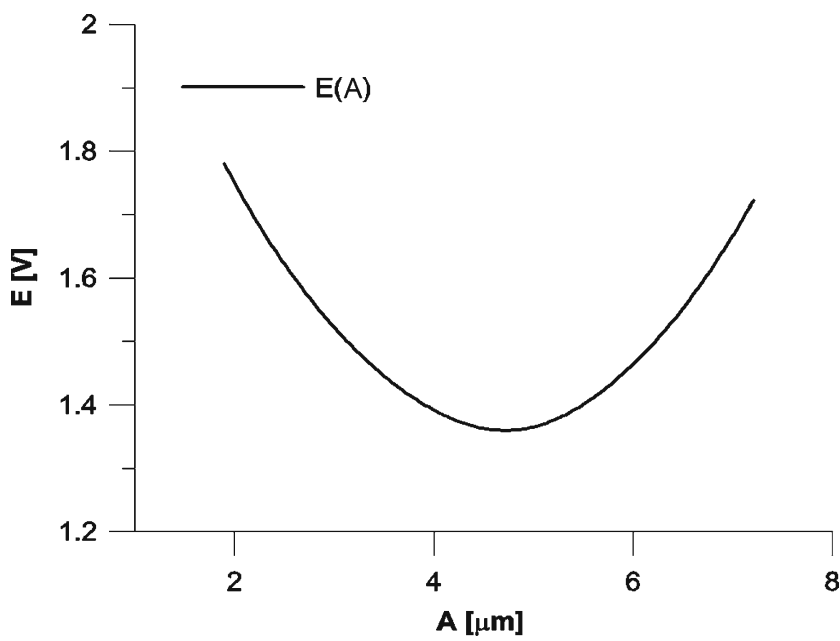

Fig. 12 Relation between amplitude of ultrasonic vibration $A$ and electrode polarisation $E$; parameters of machining: interelectrode voltage $U=15 \mathrm{~V}$, electrode feed rate $v_{f}=0.8 \mathrm{~mm} / \mathrm{min}$

that electrode ultrasonic vibrations are the reason of cavitation in the gap (which is the source of vapour generation), the $\eta k_{v}$ decrease can results from decrease of dissolution efficiency $\eta$ or electrolyte conductivity decrease $\kappa$.

Generated during machining, heat and electrolyte vapour driven by ultrasonic vibration cavitation bubbles significantly affect on electrolyte properties. Taking into account electrolyte as quasi-homogeneous media (the properties are averaged along the gap thickness) and assuming that changes of electrolyte temperature connected with electrolyte flow can be neglected (temperature depends only on time), condition of machining during one vibration period can be calculated from the following equations [11]:

$$
\begin{aligned}
& j=j_{o}(1+\alpha \Theta)(1-\beta)^{3 / 2} \\
& q_{T}=j_{o} \int_{0}^{T}(1+\alpha \Theta)(1-\beta)^{3 / 2} d t \\
& \Theta(t)=\frac{1}{\alpha}\left[\exp \left(\frac{\alpha j_{0}^{2}}{\kappa_{0} \rho_{0} C_{p}} \int_{0}^{t} \sqrt{1-\beta} \delta t\right)-1\right]
\end{aligned}
$$

where $\alpha$-temperature coefficient of electrical conductivity, $\Theta(t)$-electrolyte temperature increase in time $t, \beta$-volume concentration of the dispersed in electrolyte gas, $j$-current density and $C p$-electrolyte specific heat. Taking into account that $\beta=\alpha_{v}(50 \mu \mathrm{s}$ is to short time to hydrogen generation in gap), $S=$ $g$ (gap thickness-the same as in numerical simulation) and $U=30 \mathrm{~V}$ the Eqs. 25, 26 and 27 have been solved for vibration amplitude $A=5 \mu \mathrm{m}$. From the distribution of electric charge transferred via the gap (Fig. 13 results that ultrasonic vibration changes the 


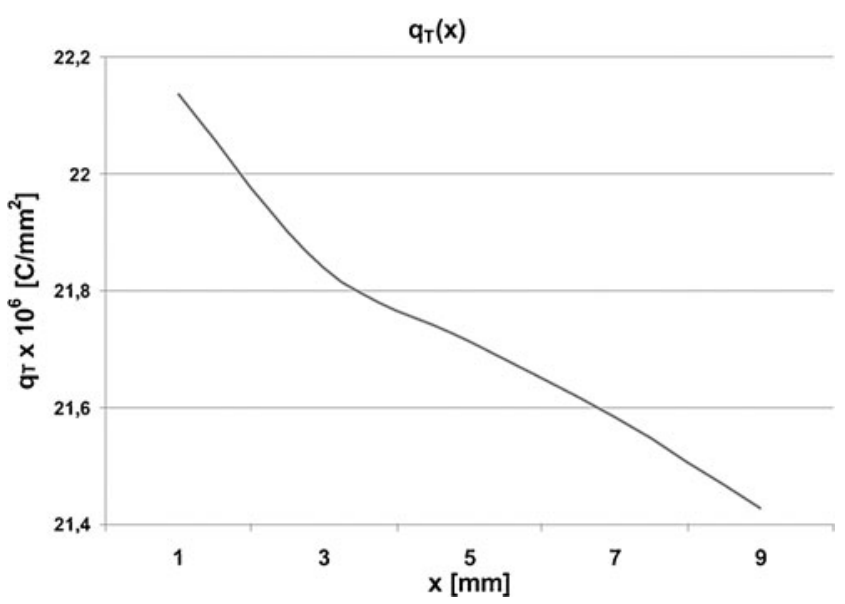

Fig. 13 Distribution of electric charge transferred through the gap during $50 \mu$ s period, $A=5 \mu \mathrm{m}, x$-length of the gap

amount of dissolved material. Amount of transferred electric charge is equivalent to mass of dissolved material; therefore, electrode vibration can be a reason of irregular anode dissolution and decrease accuracy of machining. In presented analysis, local effects of bubble collapse were omitted; however, obtained results show that not optimal selection of ultrasonic vibration amplitude for desired parameters of machining may be a reason of technological factors deterioration. One can also state that application of ultrasonic vibration in ECM needs to improve the electrolyte supply to the gap (i.e. increase electrolyte velocity).

\section{Conclusions}

Numerical investigations on USAECM prove that ultrasonic vibrations change conditions of electrolyte flow in the gap. Solution of the equations describing electrolyte flow along the gap gave possibility to obtain pressure, velocity and cavitation intensity distribution in the machining area. Numerical investigations have revealed that intensity of cavitation affects significantly conditions of dissolution process and depends on amplitude of ultrasonic vibration. Proper selection of machining parameters (especially amplitude of ultrasonic vibrations) cause that heterogeneous cavitation plays significant role in electrode potential decrease.

It is worth to emphasise that results of presented numerical modeling can be also applied during analysis of the other hybrid processes (i.e. ultrasonically assisted electrodischarge machining), and computer fluids dynamics can be successfully applied for modeling of phenomena occurring in the interelectrode gap, especially when machining is carried on in quasi-stable or unstable state.
Verification of the above presented model during machining is quite difficult. The main problem is connected with the size of interelectrode gap and short time of cavitation phenomena. Electrode tool ultrasonic vibrations influence on electrochemical dissolution process can be observed by changes of machining parameters. Presented results of USAECM research prove that ultrasonic vibrations change condition of dissolution process in interelectrode gap. In result, increase of machined allowance and removal rate is observed. Generally, the influence of the ultrasonic vibrations on the process of electrochemical machining results from the fact that they:

- Improve the heat and reactions products removal out of machining area (effect of direct mechanical electrolyte influence on electrode and machined surface)

- Support diffusion and decrease the rate of passivation processes (as a result, it is possible to decrease potential drops in the layers adjacent to electrodes)

- Change the coefficient of electrochemical machinability $\eta k_{v}$

- Create the optimal hydrodynamic conditions from surface layer point of view

Ultrasonic vibrations can also have influence on composition and proprieties of the electrolyte due to sonochemical reactions, and the course of chemical reactions in aqueous solution can be changed [14]. It should be considered in further investigations.

Acknowledgements The support of the Polish Ministry of Science and Higher Education (Grant No 7 T07D 002 18, Grant No. Nr 5 T07D 007 24) and Academic Computer Centre CYFRONET AGH (Grant No. MNiI/SGI2800/IOS/003/2004) is gratefully acknowledgement. The author wishes to thank colleagues from The Institute of Advanced Manufacturing Technology from the Department of Unconventional Technologies for the help in carrying out experiments.

Open Access This article is distributed under the terms of the Creative Commons Attribution Noncommercial License which permits any noncommercial use, distribution, and reproduction in any medium, provided the original author(s) and source are credited.

\section{References}

1. Banks C, Compton RG (2003) Voltammetric exploration and applications of ultrasonic cavitation. ChemPhysChem 4: 169-178

2. Brennen CE (1995) Cavitation and bubble dynamics. Oxford University Press, Oxford

3. Collective work (2003) Fluent 6.1 documentation

4. McGeough JA (1974) Principles of electrochemical machining. Chapman and Hall, London 
5. Perusich SA, Alkire RC (1991a) Utrasonically induced cavitation studies of electrochemical passivity and transport mechanism. I. Theoretical. J Electrochem Soc 138(3): 700-707

6. Perusich SA, Alkire RC (1991b) Utrasonically induced cavitation studies of electrochemical passivity and transport mechanism. II. Experimental. J Electrochem Soc 138(3): 708-713

7. Rajurkar K, Zhu D, McGeough J, Kozak J, Silva AD (1999) New developments in electro-chemical machining. CIRP Ann Manuf Technol 48(2):567-579

8. Ruszaj A, Zybura-Skrabalak M, Skoczypiec S, úrek R (2001) Electrochemical machining supported by electrode ultrasonic vibrations. In: Proceedings of the 13th international symposium for electromachining ISEM XIII, Fundacion Tekniker, Bilbao, Spain, vol II, pp 953-964

9. Ruszaj A, Zybura M, úrek R, Skrabalak G (2003) Some aspects of the electrochemical machining process supported by electrode ultrasonic vibration optimization. J Eng Manuf 217:1365-1371
10. Singhal AK, Athavale MM, Li H, Jiang Y (2002) Mathematical basis and validation of the full cavitation model. J Fluids Eng 124(3):617-624

11. Skoczypiec S (2006) Research on ultrasonically assisted electrochemical machining with universal electrode tool. Ph.D. thesis, Cracow University of Technology (in Polish)

12. Skoczypiec S, Ruszaj A (2005) Discussion of cavitation phenomena influence on electrochemical machining process. Int J Manuf Sci Technol 7(2):27-32

13. Skoczypiec S, Ruszaj A (2007) Application of ultrasonic vibration to improve technological factors in electrochemical machining of titanium alloys. In: Proceedings of international symposium on electrochemical machining technology INSECT 2007 (Scripts precision and microproduction engineering), vol 1. Cheminitz University of Technology, pp 143-148

14. Suslick KS, Didenko Y, Fang MM, Hyeon T, Kolbeck KJ, McNamara WB, Mdlelen MM, W Wong M (1999) Acoustic cavitation and its chemical consequences. Phil Trans R Soc Lond Ser A 357:335-353 